\title{
Effects of lactisole on pancreatic islet B-cells electrophysiology
}

\author{
Juan V Sanchez-Andres and Willy J Malaisse* \\ Department of Medicine, Universitat Jaume I, Castellan, Spain and Department of Biochemistry, Université Libre de Bruxelles, Brussels, Belgium
}

\begin{abstract}
Sucralose mimics the effects of glucose upon several variables of pancreatic islet B-cell metabolism and function, including bioelectrical activity. The present study aimed at investigating whether lactisole, which was recently found to act as an antagonist of the sweet taste receptor TIR3 in pancreatic islet B-cells, also opposes the effects of glucose and/or sucralose upon B-cell electrophysiology. A dual effect of lactisole, both inhibitory and stimulatory, was observed upon the electrical activity of mouse pancreatic islet B-cells. The present findings thus document that agents supposed to act specifically on the TIR3 sweet receptor may either mimic or oppose the effect of glucose upon islet B-cell electrical activity.
\end{abstract}

\section{Introduction}

Lactisole, a broad-acting sweet antagonist, suppresses the sweet taste of sugars, protein sweeteners and artificial sweeteners in human and other primates. The target for lactisole action in human subjects was identified as the sweet taste receptor TIR3 [1]. Taking into account these premises, lactisole was recently used as an antagonist of the sweet taste receptor in pancreatic islet B-cells in order to characterize the second messengers involved in the activation of the latter receptor [24]. It was also recently reported that sucralose, known to mimic the effects of D-glucose upon several metabolic and functional variables in pancreatic islet B-cells [5-8], also mimics the effect of the hexose upon B-cell electrical activity [9]. The effects of lactisole on pancreatic islet B-cell membrane potential remained so far to be studied. In the present report, experimental data are presented which document a more complex bioelectrical response than that expected of mice pancreatic islet B-cells to lactisole.

\section{Materials and methods}

The $\beta$-cell membrane potential was recorded from micro dissected islets of Langerhans obtained from Swiss albino mice, killed by cervical dislocation, as previously described [10]. Once isolated, the islets were fixed with micro pins to the bottom of a $50 \mu \mathrm{l}$ chamber and perifused at a flow rate of $1.0 \mathrm{ml} / \mathrm{min}$ with a modified Krebs-Ringer bicarbonate buffer containing (in $\mathrm{mM}$ ) $120 \mathrm{NaCl}, 5 \mathrm{KCl}, 25 \mathrm{NaHCO}_{3}, 1.1 \mathrm{MgCl}_{2}$ and $2.5 \mathrm{CaCl}_{2}$. This medium was continuously bubbled with a mixture of $\mathrm{O}_{2}$ (95\%) and $\mathrm{CO}_{2}(5 \%)$ to reach a 7.4 final $\mathrm{pH}$. Chamber temperature was maintained at $36 \pm 1{ }^{\circ} \mathrm{C}$. Sharp electrodes (approximately $100 \mathrm{M}$ input resistance) were pulled in a Narishige PE2 vertical puller and filled with $3 \mathrm{M}$ potassium citrate and $50 \mathrm{mM} \mathrm{KCl}$. Recordings were made with an Axoprobe amplifier (Axon Instruments), data acquisition (at a rate of $1.0 \mathrm{KHz}$ ), analysis and plotting being performed with Clamp fit version 10.4 (Molecular Devices) and Micro Cal Origin version 9.2 (Micro Cal Soft, Northampton, MA, USA). Sucralose and lactisole were purchased from Sigma (St. Louis, MO, USA) and Santa Cruz Biotechnology (Heidelberg, Germany).

\section{Results}

Figure 1, Illustrates the typical bioelectrical response of an islet B-cell to increasing concentrations of D-glucose $(3,10,15$ and $25 \mathrm{mM})$, i.e. oscillations of the membrane potential with associated calcium action potential on the top of the depolarization waves. In other words, at low glucose concentration the plasma membrane remains hyperpolarized as the result of the K-ATP activation whilst, at higher hexose concentrations, the blockade of K-ATP leads to depolarization of the plasma membrane with resulting gating of voltage-dependent calcium channels.

Figures 2 and 3 refer to experiments in which the cells were exposed to $10 \mathrm{mM} \mathrm{D}$-glucose first in the absence and later in the presence of $5 \mathrm{mM}$ lactisole. In both experiments, a transient decrease in electrical activity in response to lactisole administration was first observed. In Fig. 2, lactisole first provoked for 1-2 minutes a decrease in burst duration and, thereafter, prolonged burst duration. The removal of lactisole seemed to reverse the latter effect. Likewise, in Figure 3, lactisole first transiently decreased the burst duration and, later, obviously prolonged burst duration. Upon removal of lactisole, the electrical activity of the cell returned to its initial pattern. The concerned B-cell was adequately functional, as documented by the hyperpolarization caused by the removal of glucose from the perfusate. Figure 4 illustrates that, when lactisole was administered at a higher $10 \mathrm{mM}$ concentration to cells exposed to $10 \mathrm{mM}$ D-glucose; no transient inhibitory effect of lactisole was anymore observed, the latter agent now provoking an obvious and immediate increase in burst duration eventually leading to continuous firing.

${ }^{\star}$ Correspondence to: Willy J Malaisse, Department of Biochemistry, Université Libre de Bruxelles, 808 Route de Lennik, B-1070 Brussels, Belgium, Tel: 003225556267; E-mail: malaisse@ulb.ac.be

Key words: pancreatic insulin-producing islet cells, electrophysiology, lactisole

Received: July 06, 2018; Accepted: July 23, 2018; Published: July 30, 2018 
Lastly, Figure 5 concerns the effect of lactisole used at an even higher $20 \mathrm{mM}$ concentration upon a cell exposed to $10 \mathrm{mM}$ D-glucose first in the absence and then in the presence of $20 \mathrm{mM}$ sucralose. As expected, a major effect of sucralose was to increase the electrical bursting activity. The data listed in Table 1, which were restricted, as far as the control values recorded in the sole presence of D-glucose is concerned, to the onset of the experiment in order to avoid any interference in terms of the time course for the reversibility of sucralose action, document the statistical significance of the changes caused by sucralose in the duration of both each active phase and each complete oscillations (comprising active and silent phases), the number of action potentials in each burst, and the frequency of action potentials along either the active phases or complete periods. Only the percentage of time occupied by the active phases relative to the total period duration

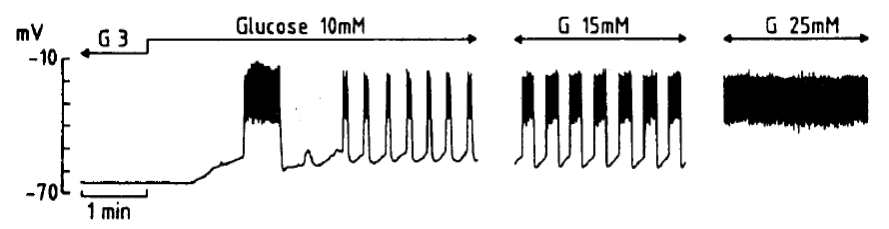

Figure 1. Representative intracellular recording of a pancreatic $\beta$-cell first exposed to a rise in extracellular D-glucose concentration from 3 to $10 \mathrm{mM}$, and later exposed to $15 \mathrm{mM}$ and then $25 \mathrm{mM}$ D-glucose

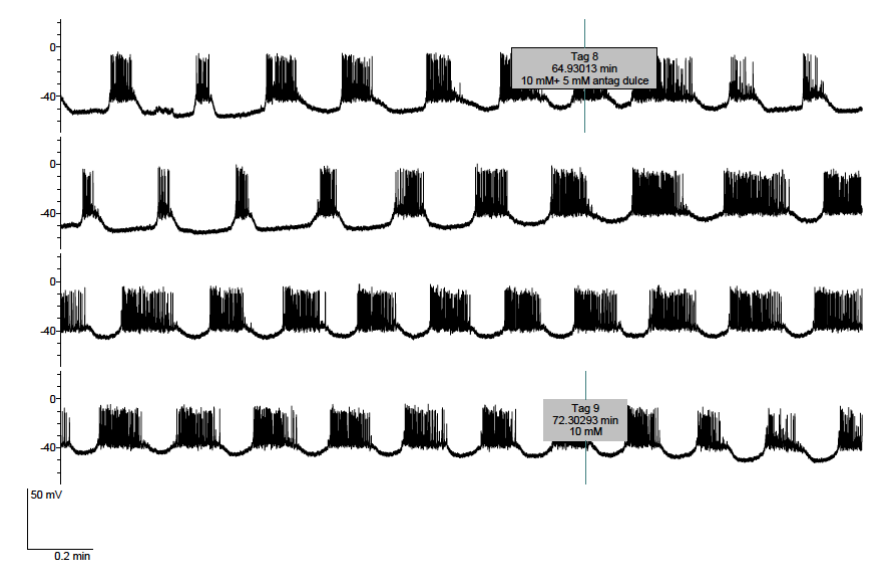

Figure 2. Effect of lactisole $(5 \mathrm{mM})$ administered from tag 8 to tag 9 upon the electrical activity of a B-cell exposed throughout the experiment to $10 \mathrm{mM}$ D-glucose

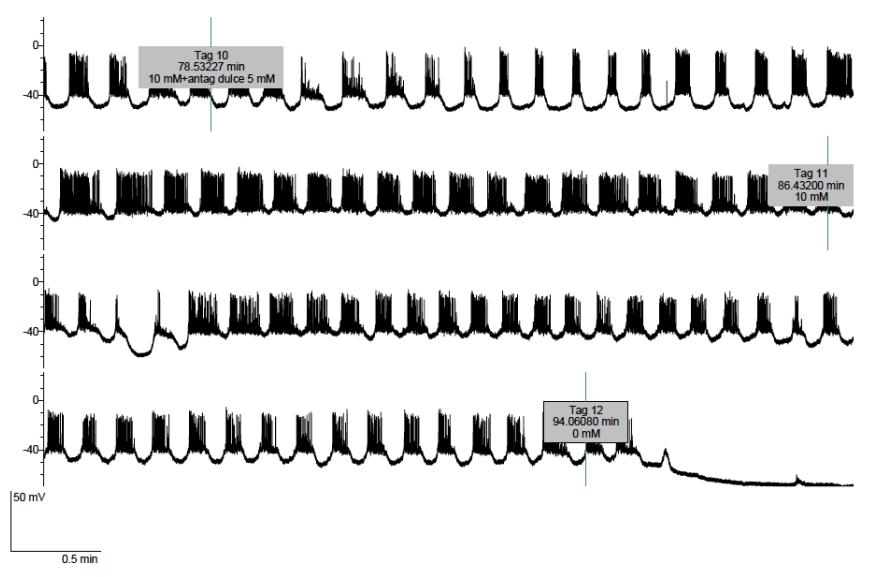

Figure 3. Effect of lactisole $(5 \mathrm{mM})$ administered from tag 10 to tag 11 upon the electrical activity of a B-cell exposed up to tag 12 to $10 \mathrm{mM}$ glucose and, thereafter, deprived of exogenous D-glucose

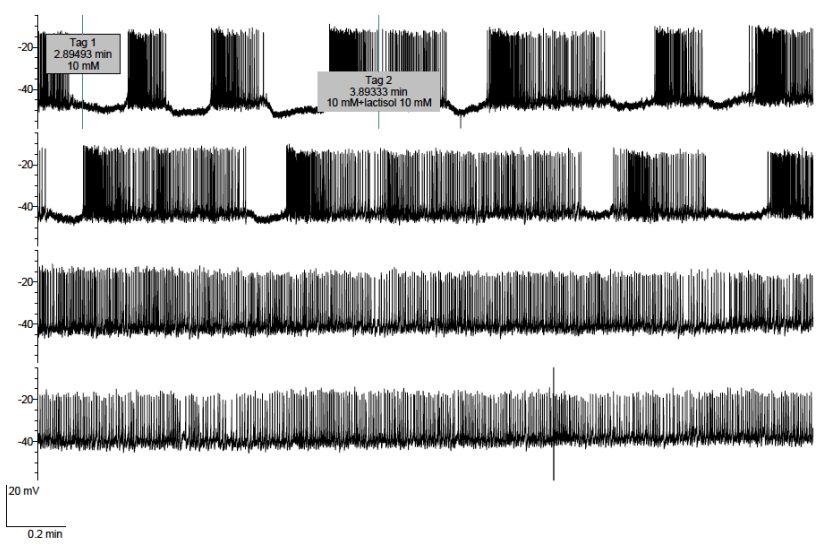

Figure 4. Effect of lactisole $(10 \mathrm{mM})$ administered from tag 2 onwards upon the electrical activity of a B-cell exposed throughout the experiment to $10 \mathrm{mM} \mathrm{D}$-glucose

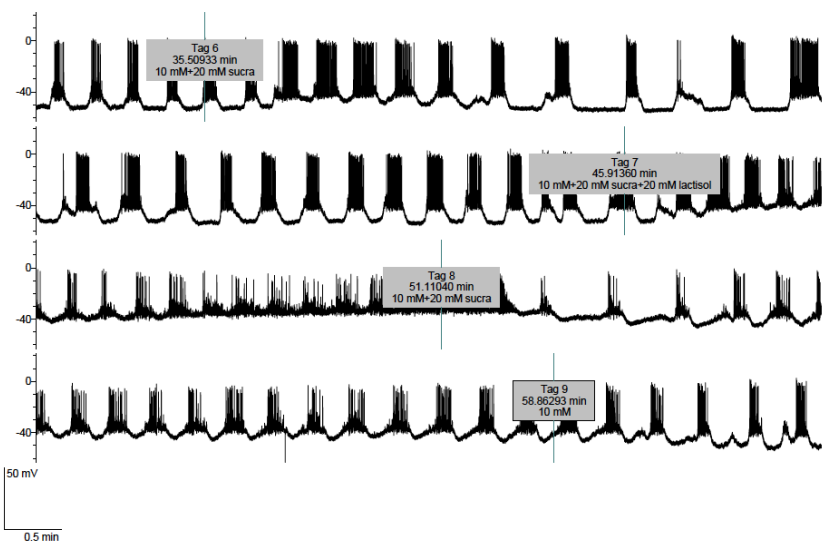

Figure 5. Effects of sucralose $(10 \mathrm{mM})$ administered from tag 6 to tag 9 and lactisole $(20 \mathrm{mM})$ administered from tag 7 to tag 8 upon the electrical activity of a B-cell exposed throughout the experiment to $10 \mathrm{mM}$ D-glucose

\begin{tabular}{|c|c|c|c|}
\hline D-glucose (mM) & 10.0 & \multicolumn{2}{|c|}{10.0} \\
\hline Sucralose (mM) & & \multicolumn{2}{|c|}{20.0} \\
\hline \multicolumn{4}{|c|}{ Time in the active phase (min) } \\
\hline 0.1 & $0.01(7)$ & $0.23 \pm 0.01(24)$ & $\mathrm{p}=0.002$ \\
\hline \multicolumn{4}{|c|}{ Duration of (active + silent) phase $(\min )$} \\
\hline 0.3 & $0.02(7)$ & $0.39 \pm 0.02(24)$ & $\mathrm{p}=0.029$ \\
\hline \multicolumn{4}{|c|}{ Percent of time in the active phase } \\
\hline & $2.4(7)$ & $61.8 \pm 2.7(24)$ & $\mathrm{p}=0.389$ \\
\hline \multicolumn{4}{|c|}{ Number of action potentials in each burst } \\
\hline 14 & $1.2(7)$ & $28.8 \pm 2.1(24)$ & $\mathrm{p}=0.001$ \\
\hline \multicolumn{4}{|c|}{ Frequency of action potentials along active phases (referred to minute) } \\
\hline 85 & $9.2(7)$ & $127.5 \pm 9.7(24)$ & $\mathrm{p}=0.031$ \\
\hline \multicolumn{4}{|c|}{ Frequency of action potentials along complete periods (referred to minute) } \\
\hline & $4.9(7)$ & $76.5 \pm 5.8(24)$ & $\mathrm{p}=0.018$ \\
\hline
\end{tabular}

failed to differ significantly in the absence or presence of sucralose. In this experiment the administration of $20 \mathrm{mM}$ lactisole to the cell exposed to both $10 \mathrm{mM}$ D-glucose and $20 \mathrm{mM}$ sucralose again only resulted in an excitatory effect, lactisole inducing further depolarization and burst cancellation, so that the cell now went into continuous firing. Such an excitatory effect of lactisole was rapidly reversed upon removal of lactisole from the perfusate. Likewise, the effect of sucralose upon burst duration was rapidly reversed upon removal of sucralose from the perfusate (Figure 5). 


\section{Discussion}

First performed by Dean and Matthews (1968) [11], intracellular recording of pancreatic islet cells electrical activity was then extensively used in several laboratories. It later felt in use, however, because of the difficulty of intracellular penetration. Nevertheless, this technique offers several advantages. Intracellular recording is made with sharp, long taped and high impact resistant electrodes, which allows a minimal invasive intervention, since intracellular dialysis does not happen contrarily to the case when using patch electrodes. The longtaped electrodes provide flexibility that permits long lasting records, usually in the 30-120 minutes range. The records are made in micro dissected islets, not requiring any enzymatic digestion, the pattern of electrical activity having been validated in vivo [12].

The present experiments first illustrate the expected graded electrical response of pancreatic islet B-cells to increasing concentrations of glucose (Figure 1). They further document that sucralose $(20 \mathrm{mM})$ increases the duration of electrical bursts in B-cells exposed to $10 \mathrm{mM}$ glucose (Figure 5). Last, they reveal that lactisole exerts, to say the least, a dual effect upon electrical activity in the islet B-cells. In the presence of $10 \mathrm{mM}$ glucose, lactisole $(5 \mathrm{mM})$ first decreased transiently and later increased in a sustained manner the duration of electrical burst (Figure 2 and 3). At a higher concentration $(10 \mathrm{mM})$ of lactisole, no inhibitory effect was anymore observed, lactisole now exerting a quite obvious excitatory effect, eventually driving the cell in continuous firing for a quite prolonged period (Figure. 4). Likewise, at an even higher concentration $(20 \mathrm{mM})$, lactisole rapidly cancelled the bursting pattern and provoked continuous firing in cells exposed to both $10 \mathrm{mM}$ glucose and $10 \mathrm{mM}$ sucralose (Figure 5).

The present results thus draw attention to a dual and time-related effect of lactisole upon B-cell electrical activity. The response to lactisole administration appears modulated by its concentration ( 5,10 or $20 \mathrm{mM})$ and the absence or presence of sucralose in association with glucose in the perfusate. The effect of lactisole is rapidly reversible (Figure. 5). Although these findings may call for more extensive investigations, they nevertheless appear compatible with the view that (i) lactisole effects are duly attributable to its binding to TIR3 receptor, (ii) the early and transient inhibitory action of lactisole upon the duration of electrical bursts could involve an increase in calcium-responsive $\mathrm{K}^{+}$ conductance resulting from a release of $\mathrm{Ca}^{2+}$ from intracellular sites [4], and (iii) exposure of pancreatic islet B-cells to lactisole may also result in an excitatory effect upon the electrical activity of these cells.

\section{References}

1. Jiang P, Cui M, Zhao B, Liu Z, Snyder LA, et al. (2005). Lactisole interacts with the transmembrane domains of human TIR3 to inhibit sweet taste. J Biol Chem 280: 15238-15246. [Crossref]

2. Ohtsu Y, Nakagawa M, Nagasawa M, Takeda S, Arakawa H, et al. (2014). Diverse signaling systems activated by the sweet taste receptor in human GLP-1 secreting cells. Mol Cell Endocrinol 394: 70-79. [Crossref]

3. Hamano K, Nakagawa Y, Ohtsu Y, Li L, Medina J, et al. (2015) Lactisole inhibits the glucose-sensing receptor TIR3 expressed in mouse pancreatic $\beta$-cells. J Endocrinol 226: 57-66. [Crossref]

4. Nakagawa Y, Nagasawa M, Medina J, Konjima I (2015) Glucose evokes rapid $\mathrm{Ca}^{2+}$ and cyclic AMP signals by activating the cell-surface glucose-sensing receptor in pancreatic $\beta$-cells. PloS ONE 10: e0149053. [Crossref]

5. Nakagawa Y, Nagasawa M, Yamada S, Hara A, Mogani H, et al. (2009) Sweet taste receptor expressed in pancreatic beta-cells activate the calcium and cyclic AMP signaling systems and stimulates insulin secretion. PloS ONE 4: e5106. [Crossref]

6. Kojima I, Nakagawa Y (2011) The role of the sweet taste receptor in enteroendocrine cells and pancreatic $\beta$-cells. Diabetes Metab J 34: 451-457. [Crossref]

7. Nakagawa Y, Nagasawa M, Mogami H, Lohse M, Ninomiya Y, et al. (2013) Multimodal function of the sweet taste receptor expressed in pancreatic $\beta$-cells: generation of diverse patterns of intracellular signals by sweet agonists. Endocrinol J 60: 1191-1206. [Crossref]

8. Nakagawa Y, Ohtsu Y, Nagasawa M, Shibata H, Kojima I (2013) Glucose promotes its own metabolism by acting on the cell-surface glucose-sensing receptor TIR3. Mol Cell Endocrinol 394: 70-79. [Crossref]

9. Sanchez AJV, Malaisse WJ (2015) Characterization of the sweet taste receptor electrophysiology in pancreatic beta cells. Comm. 51st Annual Meeting of the European Association for the Study of Diabetes.

10. Sanchez AJV, Ripoll C, Soria B (1988). Evidence that muscarinic potentiation of insulin release is initiated by an early transient calcium entry. FEBS Lett 231: 143-147.

11. Dean PM, Matthews EK (1968) Electrical activity in pancreatic islet cells. Nature 219: $389-390$

12. Sanchez AJV, Gomis A, Valdeolmillos M (1995). The electrical activity of mouse pancreatic beta-cells recorded in vivo shows glucose-dependent oscillations. J Physiol 468: 223-228. [Crossref]

Copyright: (C2018 Sanchez-Andres JV. This is an open-access article distributed under the terms of the Creative Commons Attribution License, which permits unrestricted use, distribution, and reproduction in any medium, provided the original author and source are credited. 